\title{
Glycemic Index for the Management of Chronic Disease: Why Certain Foods Like Raisin may be Beneficial
}

\author{
Stacey J. Bell*
}

Nutrition Consultant, Boston, MA 02116, USA

\begin{abstract}
The glycemic index (GI) refers to impact of the ingestion of carbohydrate-containing foods on blood sugar concentrations. High-GI foods increase blood glucose levels more and for a longer time, than those with low GIs. It appears that those who adopt a low-GI diet have a reduced risk of heart disease, type 2 diabetes mellitus, and obesity. Carbohydrate-containing foods on a low-GI diet include an abundance of fruits and vegetables, lesser amounts of grains including whole grains, and dairy products; those rich in sugar are to be consumed sparingly. Despite tasting sweet, raisins have a low-to-moderate GI (50-64). Raisins can be substituted for other high-GI snack foods, as well as serve as preexercise snacks. Thus, those wishing to adopt a low-GI diet should consider raisins as a healthy fruit serving to be used as a snack or with a meal.
\end{abstract}

Keywords: glycemic index, raisins, type 2 diabetes mellitus, obesity, cardiovascular disease.

\section{INTRODUCTION}

As one ages, diet plays an important role in determining the risk of chronic diseases such as cardiovascular disease (CVD), type 2 diabetes mellitus, and obesity [1]. Although the ideal diet to consume over a lifetime is debatable, most agree that consuming an energy-dense Western diet that is rich in fat, low in fiber, and devoid of many essential nutrients is not healthy [1]. An international panel of experts identified seven evils of this type of diet and found a high glycemic index (GI) to be one of them. In this review, data are presented to support consumption of a low-GI diet to maintain health. How to follow a low-GI diet, which includes raisins, is provided. The emphasis on this dried fruit arose because some researchers questioned whether raisins, given their sweet flavor, have low-GIs like other fruits. In addition, many snack foods have high GIs, which poses a unique problem. Instead of tiding one over between meals, such foods end up stimulating appetite (see below). Raisins are reviewed herein because they offer both a sweet, snacklike flavor and have a low GI.

\section{DEFINITION}

The GI concept was set forth in the early 1980s as a way for researchers to better control blood sugar fluctuations during the day in patients with diabetes [2,3]. The GI relates to the rate at which recently ingested available (non-fiber) carbohydrates appear in the blood as glucose. The test has been validated by an international group of researchers using only capillary blood, thereby facilitating measuring the GI of many foods [4]. To date, over 1,000 foods have been measured.

The GI is expressed as a percentage: $\mathrm{A} / \mathrm{B} * 100$ where

*Address correspondence to this author at the Nutrition Consultant, Boston, MA 02116, USA; Tel: 617 999-6150; E-mail: staceyjbell@yahoo.com
A is the integrated increase in blood glucose concentration during a two-hour period after a known quantity of ingested available carbohydrate (usually 50 grams)

$\mathrm{B}$ is the integrated increase in blood glucose concentration during a two-hour period after a known quantity of a reference food is ingested (50 grams of glucose or white bread)

The GIs of foods typically range from 20 to 100 (Table 1) [5]. Other dietary components such as fiber and fat decrease the expected GI. Some foods have virtually no glycemic effect like meats, oils, and non-starchy vegetables. A low-GI diet predominately includes low-GI foods and some middle-GI foods like rice; high-GI foods like sugared carbonated beverages should be used sparingly. When middleGI and high-GI foods are consumed, it is best to spread them out throughout the day or to consume with low-GI foods to avoid surges in both blood glucose and insulin concentrations.

Table 1. The Glycemic Index of Food Per 50 Gram of Available Carbohydrate*

\begin{tabular}{|l|l|}
\hline FOOD & GLYCEMIC INDEX (based on glucose) \\
\hline \hline Peanuts & 14 \\
\hline Lentils & 30 \\
\hline Macaroni & 47 \\
\hline RAISINS & $50^{\wedge}, 62^{\wedge}, 64$ \\
\hline Banana & 52 \\
\hline Rice, boiled white & 64 \\
\hline Whole meal bread & 71 \\
\hline Pretzels & 83 \\
\hline Baked potato & 85 \\
\hline Corn flakes & 92 \\
\hline *[5]; ^[49]. &
\end{tabular}


Using the GI in meal planning is problematic because the GI is based on 50 grams of available carbohydrate, which is not usually the amount consumed in a typical serving. Researchers came up with a new term called the glycemic load (GL) [6-8]. This takes into account the effect on blood sugar levels of a typical serving of a food. The sum of all of the GLs in a day can then determine the overall glycemic effect (Table 2). The dietary GI can also be computed by summing the GIs of the foods consumed in a single day. The glycemic load is calculated:

$\mathrm{A} * \mathrm{~B} / 100$, where

A is the glycemic index of a food (\%)

B is the grams of available carbohydrate in that food

The GL and GI often trend in the same direction, but not always. For example, carrots have a high GI (71) but a low GL (4) [9]. The difference stems from the fact that the GI is calculated from $50 \mathrm{~g}$ of available carbohydrate from carrots, which is four cups. A typical serving of carrots is about onehalf cup. Carrots are high in fiber and water, which contribute to weight but do not affect blood sugar concentrations. Fruits are also rich in fiber and water and thus have higher GIs than GLs. For this reason, the GL has also been adopted by nutritionists for meal planning and research studies.

\section{PHYSIOLOGICAL EFFECTS}

High GI foods evoke a higher response in glucose and insulin concentration after ingestion compared to foods with low-GIs. A low-GI food or meal does not induce such dramatic hormonal and blood sugar swings. Most low-GI foods take longer to digest and absorb, thereby minimizing hyperglycemia and hyperinsulinemia. Hunger is avoided because stored substrates can readily be mobilized to meet energy needs. The physiological responses to consuming foods with different GIs can be considered in three phases [9, 10]. Within two hours of ingesting a high-GI food or meal, a surge in both blood glucose and insulin occurs. Blood levels of these are twice what would occur after consumption of a eucaloric, low-GI food or meal. Insulin is an anabolic hormone, which stimulates substrate storage of fat into adipocytes and carbohydrate into muscle and liver glycogen.
Regular consumption of high-GI meals can precipitate insulin resistance, because the pancreas is called upon to secrete supra-normal amounts of insulin over a long period of time. The pancreas eventually becomes exhausted, and over time, is unable to secrete ample insulin to meet demand. This is thought to be one of the precipitating factors leading to type 2 diabetes.

During the second phase between two and four hours, the blood is nearly devoid of nutrients. As a result, small amounts of glucagon are released to counter act the high insulin concentrations. Blood glucose levels continue to fall and the brain, which uses glucose as its primary fuel, senses the lack of this substrate. In addition, free fatty acids are also suppressed, which is the body's other major fuel source. These physiologic situations are equated to hunger. In the final phase after four to six hours, the counter regulatory hormones (e.g., glucagon, growth hormone) are released in full force, in an attempt to release stored energy from glycogen (glucose) and adipocytes (fat). As long as insulin concentrations remain elevated, substrate release is blunted and hunger remains. It is possible that long-term consumption of a high-GI diet leads to chronic hyperinsulinemia and insulin resistance. Eventually, beta cell failure occurs from the diet and genetic and lifestyle factors, leading to type 2 diabetes.

\section{EFFECT OF GLYCEMIC INDEX OF THE DIET ON HEALTH}

\section{Satiety}

The GI of the diet affects hunger and satiety $[10,11]$. Consumption of high-GI foods promotes a more rapid return of hunger than an isocaloric amount of low-GI foods because a rapid decline in blood glucose from peak levels occurs consistently after consumption of high-GI foods as a result of the extreme counterregulatory hormonal responses that are activated to normalize high levels of circulating glucose [11]. Over 20 articles have evaluated the effect of dietary GI on satiety and hunger $[10,11]$. The lower the GI, the earlier someone feels full (satiation) and the less sensation of hunger there is between meals. On average, including just one low-GI meal resulted in consuming $20 \%$ fewer calories during that day. Eating all meals from low-GI foods over six

Table 2. Glycemic Index and Glycemic Loads of Selected Food Groups*

\begin{tabular}{|l|l|l|}
\hline $\begin{array}{l}\text { FOOD CATEGORY } \\
\text { (sample serving size) }\end{array}$ & $\begin{array}{l}\text { GLYCEMIC INDEX } \\
\text { (compared to glucose and based on 50 g } \\
\text { available carbohydrate) }\end{array}$ & $\begin{array}{l}\text { GLYCEMIC LOAD } \\
\text { (based on typical serving size and glycemic } \\
\text { index) }\end{array}$ \\
\hline \hline Dairy products (1 cup of milk) & $20-40$ & $<10$ \\
\hline Vegetables; non-starchy & Insignificant & Insignificant \\
\hline Vegetables; starchy (1/2 cup potato) & $60-90$ & $10-25$ \\
\hline Legumes, nuts ( most legumes $2 / 3$ cup) & $25-45$ & $<5$ to 15 \\
\hline Fruits (1/2 cup strawberries) & $30-60$ & $5-15$ \\
\hline RAISINS & $50^{\wedge}, 62^{\wedge}, 64$ & \\
\hline Sugary, carbonated beverages (1 cup) & 63 & 16 \\
\hline Snack foods; salty, sweet, high-fat (highly variable) & $>50$ & $10-25^{\wedge}$ \\
\hline
\end{tabular}

$*[5] ; \wedge[49]$. 
days resulted in a $25 \%$ reduction in total spontaneous energy intake [12, 13]. However, others [14] were not able to confirm that high- or low-GI foods had any effect on appetite.

\section{Weight}

The GI or GL of the diet has been shown to have a profound impact on obesity [15]. The GL of the diet rose $22 \%$ between 1980 and 1990 in the United States. During that same time, the percentage of overweight women increased by $38 \%$. Whether these two things are causal is not known; $41 \%$ of women stopped smoking during the same period, which also could explain some of the weight gain.

Adolescents who adhered to a low-GI diet experienced weight loss over four months in one study, and in one year in another $[16,17]$. In both studies, those assigned to the lowGI group had no constraints imposed on energy intake; the control group (low-fat, high-GI) had such a restriction. Paradoxically, the low-GI group ate fewer calories $(1,439 \mathrm{kcal}$ vs. 1,621 kcal) and complained less of hunger, than the lowfat, high-GI group [17].

Even substituting one meal (breakfast) with low-GI food choices can lower fasting blood glucose levels and improve satiety throughout the day in overweight and obese adult subjects [18]. Other investigators have seen decreases in serum leptin levels in response to a low-GI diet, but not to a high-GI diet. High leptin levels are associated with hyperinsulinemia and obesity [19]. Leptin may be considered to be a surrogate marker of obesity, because it is an adipose-derived factor that acts in the hypothalamus to depress resting energy expenditure. Resting energy expenditure declined significantly less $(\mathrm{P}=0.04)$ when a low-GI diet was consumed, compared to one with a high-GI [12]. All of these findings suggest that a low-GI diet appears to be of benefit for those trying to lose weight.

Despite these promising results, others failed to show any benefit of a low-GI diet on weight loss compared to a typical, low-fat, high-GI heart-healthy diet [20-23]. Regardless of the effect of a low-GI diet on weight loss, it is clear that adopting one improves overall the overall nutrient quality of the diet [24, 25]. After just six days of consuming a low-GI diet, the total antioxidant capacity of the blood increased [26]. Despite no change in the standard markers of disease (e.g., blood sugar or cholesterol levels), the early change in total antioxidant capacity can be considered a surrogate for the cascade of metabolic events linking dietary GI to risk of heart disease and diabetes. Healthy, nutrient-dense, low-fat foods for the most part have low-GIs. Such foods should provide the majority of the energy for anyone trying to lose weight, or maintain weight that was recently lost.

\section{Type 2 Diabetes}

Most of the studies evaluating the effect of a low-GI/GL diet on health were conducted in patients with or at risk of type 2 diabetes. Epidemiological data in healthy women [27] and men [28] showed that dietary GL was related to disease risk and surrogate markers of disease process. For men, levels of adiponectin were $18 \%$ lower for the group who consumed the lowest GL diet compared to those who consumed the highest. Adiponectin is a cytokine secreted by adipose tissue and provides a target for treating cardiovascular complications in diabetic patients [28]. For women, a high-GL, low-fiber diet increased the risk of type 2 diabetes over twofold compared to those who ate a low-GL diet with little dietary fiber [27]. This risk was significant after adjustment for age, body mass index, smoking, physical activity, family history of diabetes, alcohol, and total energy intake. Another study found that just eating a high-fiber diet was a better predictor than dietary GI of who would develop insulin resistance and hence, diabetes [29]. Interestingly, older individuals (70-80 years of age) did not appear to reap the same benefit in mitigating disease risk as younger individuals following a low-GI diet. Nevertheless, it appears that adopting a low-GI diet early in life reduces the risk of developing type 2 diabetes.

Based on a meta-analysis, patients who have type 2 diabetes, choosing low-GI foods instead of high GI ones, had a small, but clinically useful effect on glycemic control [30]. The low-GI diet was associated with a 7.4 percent reduction in HbA1c. This benefit mimics outcomes of some pharmacological approaches. Later it was shown that patients with type 2 diabetes $(n=210)$, who followed a low-glycemic load diet for six months, also experienced a significant decrease in $\mathrm{HbA} 1 \mathrm{c}$ and an increase in high-density lipoprotein (HDL) cholesterol [31]. In the same study, another group of patients was randomized to a high-fiber, cereal-based diet. That group did not experience these beneficial changes, suggesting that the low-glycemic diet has unique properties. A longterm (12 months) study in 162 patients with type 2 diabetes consumed either a high-carbohydrate, low-GI diet, or a lowcarbohydrate diet [32]. Those in the high-carbohydrate, lowGI diet experienced improvement in beta cell function, a positive finding for those with diabetes [32]. These studies seem to suggest that the low-GI diet offers unique benefits which make it a better choice for patients with diabetes over either avoiding all carbohydrates or eating a high-fiber diet from cereal sources.

Many researchers found that the dietary GI and GL has a positive effect on lowering the risk of diabetes [33]. Unlike the findings of Wolever [32], others [33] have found that a higher intake of cereal fiber has been consistently associated with lower diabetes risk. For patients with, or at risk of diabetes, replacement of high-GI carbohydrates with low-GI ones will improve glycemic control. Among patients treated with insulin, a low-GI diet will reduce hypoglycemic episodes. Small dietary changes include replacing white flour and potatoes with whole-grain, minimally-refined cereal products. Limiting high-GI foods and increasing intake of low-GI ones is also important. These same dietary changes also reduce cardiovascular disease risk.

\section{Cardiovascular Disease}

The American Heart Association (AHA) recommends a low-fat, high-carbohydrate diet to reduce the risk of cardiovascular disease (CVD), and for those with CVD, to help manage it. However, this diet has a high -GI, which may be cause for concern [24, 25, 34]. Higher postprandial blood glucose and insulin levels found in a high-GI diet may affect the risk of CVD [9]. Possible mechanisms as to why a highGI diet increases the risk of CVD include: postprandial hyperglycemia, hyperinsulinemia, hypertriglyceridemia, and high low-density lipoprotein levels.

A meta-analysis consisting of 16 studies showed that adopting a low-GI diet was associated with significantly 
lower total cholesterol concentrations $(\mathrm{P}<0.0001)$ and a trend to lowering low-density lipoprotein (LDL) cholesterol $(\mathrm{P}=0.06)$ [35]. No changes were observed in HDL cholesterol or triglyceride levels. Admittedly these are surrogate markers of disease, but epidemiological data support a role for a low-GI diet in reducing the risk of CVD. Between the lowest and highest quintile for overall dietary GL, the risk of CVD doubled in women, suggesting a relationship between high dietary GL and CVD risk, independent of known coronary risk factors [36]. This significant risk $(\mathrm{P}$ trend $<0.0001)$ was established after adjustment for age, smoking status, and total energy intake. Classifying carbohydrates merely according to simple or complex did not yield these same significant findings. A subset of these women had C-reactive protein (CRP) concentration data available. CRP increased at each quintile increase of dietary GL. When coupled with increasing body mass indexes (BMIs), the positive relationship between CRP and risk of CVD became stronger, showing that obese individuals may gain further benefit from a low-GI diet compared to those of normal weight.

A subsequent study from the same laboratory found slightly different results [37]. Dietary GL was a stronger predictor of HDL cholesterol and LDL:HDL cholesterol ratio than dietary GI in a group of normal-weight, middle-aged and older women. However, dietary GI was associated with LDL cholesterol and CRP concentrations. In this group of middle-aged and older women, dietary GL and GI appeared to be more influential in reducing CVD risk in normal weight women, rather than ones who are overweight, as previously shown $[36,37]$. More work is needed to tease out these conflicting results in women.

Even within six days, the GI effect on CVD risk can be ascertained [13]. Healthy subjects (12 overweight males) were randomized to a low-GI or a high-GI diet (the AHA diet), and then crossed over to the other regimen. During the AHA diet, the HDL-cholesterol decreased, which worsened the total cholesterol/HDL-cholesterol ratio - a risk factor for CVD. Serum triglycerides increased by $28 \%$. In contrast, during the low-GI phase, serum triglycerides decreased $35 \%$, peak particle LDL cholesterol size increased by $1.6 \%$, and plasma insulin levels were lower for fasting and during the day measurements. These changes reduced CVD risk.

Other longer studies lasting 10 weeks [38], 12 weeks [39], or one year [40], corroborated these aforementioned short-term results - a low-GI diet has a beneficial effect on reducing CVD risk and the AHA diet does not. However, recently, others found no differences between feeding overweight and obese men at risk of CVD disease a low- vs. high-GI diet, so clearly more work in this area is needed before changes are made to the existing AHA dietary recommendations [41].

\section{Other Conditions}

A comprehensive meta-analysis revealed that dietary GI was positively related to colorectal and endometrial cancer risk, but that other types (i.e., breast, pancreatic) were not associated with it [42]. It is possible the differences are related to the limited number of studies or calculation accuracy of GI [43]. Others found that age-related maculopathy (ARM) was related to the dietary GI, but not to total carbohydrate intake [44]. The risk of developing ARM doubled between the lowest and highest tertile for dietary GI. However, dietary GL did not appear to be related to the risk of cataracts in men and women who were followed for over ten years [45]. There appears to be some benefit for exercise; a low-GI meal seemed to facilitate the uptake of fatty acids into the muscles, to theoretically improve endurance [46]. However, the GI of breakfast cereal was found to vary depending upon the fitness level [47]. The same test cereal produced higher GIs in sedentary, young males compared to endurance-trained male athletes. More work is needed to see if these same results are true of women and the elderly.

\section{RAISINS: DO THEY FIT INTO A LOW-GI DIET?}

Admittedly there is some disagreement among the various studies as whether a low-GI diet reduces the risk of obesity, CVD, and diabetes, or if it is the optimal diet if one already has one of these conditions. Adopting a low-GI diet can provide a healthy, nutrient-dense, low-fat, and satisfying diet (Table 3) [48]. The diet is rich in fruits and vegetables, has ample protein from dairy, vegetarian and meat sources, and has modest amount of whole grains; sugar-laden foods are kept to a minimum. Such a diet is suitable for those who want to maintain good health and for those with chronic conditions such as type 2 diabetes and heart disease.

Fruit should be consumed twice a day on a low-GI diet, and one serving can come from raisins. Based on the $\mathrm{Na}$ tional Health \& Nutrition Examination Survey (NHANES)

Table 3. An Example of a Diet with a Low Glycemic Index

\begin{tabular}{|l|l|l|}
\hline FOOD GROUP & NUMBER OF SERVINGS PER DAY & GLYCEMIC RATING* \\
\hline \hline Dairy products & 2 to 3 & Low \\
\hline Non-starchy vegetables & Unlimited & Low \\
\hline $\begin{array}{l}\text { Protein (meats and vegetarian sources including legumes, nuts, } \\
\text { seeds) }\end{array}$ & $\begin{array}{l}\text { One serving at each meal to yield 60-100 g dietary } \\
\text { protein per day }\end{array}$ & Low \\
\hline Fruits including raisins & 2, of which one can be raisins & Low-intermediate \\
\hline Starchy vegetables, whole grains & $6-10$ & Intermediate \\
\hline $\begin{array}{l}\text { Refined carbohydrates from carbonated beverages, pastries, } \\
\text { donuts, salty snacks, candy }\end{array}$ & Keep to a minimum & High \\
\hline
\end{tabular}

*Low < 70; Intermediate 70-90; and High > 90. 
1999-2004 data base, individuals who regularly consumed 1/8 cup of raisins had higher nutrient intakes of most essential nutrients, weighed less, and had smaller waist circumferences compared to those who do not consume raisins regularly [49]. Thus, including raisins in the diet may improve its overall quality.

Some may worry that since raisins are so sweet that they will have a high GI. However, this is not the case. Recently the GI was determined to be low $(\leq 55)$ for healthy subjects and for those with prediabetes [50]. For trained athletes, the measured GI was considered moderate $(\mathrm{GI}=55-69)$. Others have found raisins to have a moderate GI as well $(\mathrm{GI}=64)$ [5]. The insulin response to raisins was low-to-moderate in healthy and patients with prediabetes, but it was 2.5 -fold lower in trained athletes. Most athletes have enhanced insulin sensitivity and are better able to dispose of glucose than untrained individuals, so these results were expected.

Despite the slightly higher insulin response seen in healthy individuals and in those with prediabetes, there appears to be little cause for concern for eating raisins [51]. In patients with type 2 diabetes, and thus poor insulin sensitivity, including raisins as part of a healthy, low-GI diet lead to health improvements. The patient education on how to follow a low-GI diet appeared to be simple. After nine weeks, the patients ate a better diet (lower in GI, lower fat, higher fiber), lost weight and abdominal fat, and experienced favorable changes in metabolic parameters (fasting blood glucose, fructosamine, insulin sensitivity factor) compared to not following a low-GI diet. As part of the low-GI diet, the subjects focused on eating more fruit by including dried fruits like raisins. Thus, inclusion of raisins as part of a low-GI diet for patients with type 2 diabetes did not negatively affect insulin function or glycemic response. Whether these same benefits are seen in obesity or in patients with CVD is unknown.

The two servings of fruit for a low-GI diet can be consumed at meals or as snacks. Raisins particularly lend themselves to snacking, because they are sweet, portable, and do not increase the risk of dental caries [52]. Snacking in advance of exercise was evaluated in 115 children, who were randomized to three regimens one hour before playing soccer [53]. The eucaloric snacks were: (1) a nutrient dense/high flavonoid HF) raisin nut bar; (2) a low flavonoid (LF) peanut butter graham bar, and (3) a low flavonoid/high sugar (LF/HS) rice cereal bar. Children spent $33 \%$ of the game in moderate to vigorous activity and $49 \%$ in sedentary activity; this pattern did not differ among the snack groups. All groups experienced similar increases in blood glucose and cortisol and decreases in IgA after ingesting after snacks. However, those in the LF/HS group reported more symptoms of fatigue, which may have been related to the high sugar and GI and lack of flavonoids in the bar. When choosing pre-exercise snacks, it appears prudent to avoid those with high-GIs and poor nutritive content to avoid early onset fatigue.

Adults who consumed raisins in advance of exercise also seemed to benefit [54]. Eight cyclists consumed either raisins (low-moderate GI) or a sports gel (high-GI), 45 minutes before exercising at a sub-maximal rate for 45 minutes followed by a 15-minute performance trial [53]. Performance and metabolic parameters did not differ between the two diets. Sports gels are costly and touted to improve perform- ance over conventional pre-exercise snacks. However, these results do not support this contention. Thus, there appears to be a role for using raisins, which were equally effective and less costly, than sports gels.

\section{SUMMARY}

The typical American diet has a high-GI, which has been associated with poor satiety, weight gain, and a risk of chronic diseases such as type 2 diabetes and CVD. Adopting a low-GI diet provides all essential nutrients and reduces these risks. Snacking is particularly difficult because most snack foods have high GIs. Raisins have low-to-moderate GIs, and one box (1.5 ounces) is considered a serving of fruit. They are not cariogenic or foster inappropriate weight gain in children when used as a snack. Thus, raisins can be included as part of a low-GI diet.

\section{CONFLICT OF INTEREST}

Dr. Bell is a nutritional consultant to the California Raisin Marketing Board, who funded preparation of this manuscript.

\section{REFERENCES}

[1] Cordain L, Eaton SB, Sebastian A, et al. Origins and evolution of the Western diet: health implications for the $21^{\text {st }}$ century. Am J Clin Nutr 2005; 81: 341-54.

[2] Jenkins DJ, Wolever TM, Taylor RH, et al. Glycemic index of foods: a physiologic basis for carbohydrate exchange. Am J Clin Nutr 1981; 34: 362-6.

[3] Wolever TMS, Jenkins DJA, Jenkins AL, Josse RG. The glycemic index: methodology and clinical importance. Am J Clin Nutr 1991; 54: 846-54.

[4] Wolever TMS, Vorster HH, Bjorck I, et al. Determination of the glycaemic index of foods: interlaboratory study. Eur J Clin Nutr 2003; 57: 475-82.

[5] Foster-Powell K, Holt SHA, Brand-Miller JC. International table of glycemic index and glycemic load values: 2002. Am J Clin Nutr 2002; 76: 5-56.

[6] Salmeron J, Manson JE, Stampfer MJ, Colditz GA, Wing AL, Willett WC. Dietary fiber, glycemic load, and risk of non-insulindependent diabetes mellitus in women. JAMA 1997; 277: 472-7.

[7] Liu S, Manson JE, Stampfer MJ, et al. Dietary glycemic load assessed by food-frequency questionnaire in relation to plasma highdensity-lipoprotein cholesterol and fasting plasma triacylglycerols in postmenopausal women. Am J Clin Nutr 2001; 73: 560-6.

[8] Ebbeling CB, Leidig MM, Sinclair KB, Seger-Shippee LG, Feldman HA, Ludwig DS. Effects of an ad libitum low-glycemic load diet on cardiovascular disease risk factors in obese young adults. Am J Clin Nutr 2005; 81: 976-82.

[9] Ludwig DS. The glycemic index: physiological mechanisms relating to obesity, diabetes, and cardiovascular disease. JAMA 2002; 287: 2414-23.

[10] Ludwig DS. Dietary glycemic index and obesity. J Nutr 2000; 130: 280S-3S.

[11] Roberts SB. High-glycemic index foods, hunger, and obesity: Is there a connection? Nutr Rev 2000; 58: 163-9.

[12] Agus MSD, Swain JF, Larson CL, Eckert EA, Ludwig DS. Dietary composition and physiologic adaptations to energy restriction. Am J Clin Nutr 2000; 71: 901-7.

[13] Dumesnil JG, Turgeon J, Tremblay A, et al. Effect of a lowglycaemic index-low-fat-high protein diet on the atherogenic metabolic risk profile of abdominally obese men. Br J Nutr 2001; 86: 557-68.

[14] Alfenas RCG, Mattes RD. Influence of glycemic index/load on glycemic response, appetite, and food intake in healthy humans. Diabet Care 2005; 28: 2123-9.

[15] Hu FB, Stampfer MJ, Manson JE, et al. Trends in the incidence of coronary heart disease and changes in diet and life style in women. N Engl J Med 2000; 343: 530-7. 
[16] Speith LE, Harnish JD, Lenders CM, et al. A low-glycemic index diet in the treatment of pediatric obesity. Arch Pediatr Adolesc Med 2000; 154: 947-51.

[17] Ebbeling CB, Leidig MM, Sinclair KB, Hangen JP, Ludwig DS. Reduced glycemic load in the treatment of adolescent obesity. Arch Pediatr Adolesc Med 2003; 157: 773-9.

[18] Pal S, Lim S, Egger G. The effect of a low glycaemic index breakfast on blood glucose, insulin, lipid profiles, blood pressure, body weight, body composition and satiety in obese and overweight individuals: a pilot study. J Am Coll Nutr 2008; 27: 387-93.

[19] Pereira MA, Swain J, Goldfine AB, Rifai N, Ludwig DS. Effects of a low-glycemic load diet on resting energy expenditure and heart disease risk factors during weight loss. JAMA 2004; 292: 2482-90.

[20] Davis MS, Miller CK, Mitchell DC. More favorable dietary patterns are associated with lower glycemic load in older adults. J Am Diet Assoc 2004; 104: 1828-35.

[21] Raatz SK, Torkelson CJ, Redmon JB, et al. Reduced glycemic index and glycemic load diets do not increase the effects of energy restriction on weight loss and insulin sensitivity in obese men and women. J Nut 2005; 135: 2387-91.

[22] Carels RA, Darby LA, Douglass OM, Cacciapaglia HM, Rydin S. Education on the glycemic index of foods fails to improve treatment outcomes in a behavioral weight loss program. Eat Behav 2005; 6: 145-50.

[23] Pi-Suyner FX. Glycemic index and disease. Am J Clin Nutr 2002; 76: 290S-8S.

[24] Bell SJ, Sears B. Low-glycemic-load diets: Impact on obesity and chronic diseases. Crit Rev Food Sci Nutr 2003; 43: 357-77.

[25] Bell SJ, Sears B. A proposal for a new national diet: A lowglycemic load diet with a unique macronutrient composition. Metab Syndr Rel Disord 2003; 1: 199-208.

[26] Botero D, Ebbeling CB, Blumberg JB, et al. Acute effects of dietary glycemic index on antioxidant capacity in a nutrient-controlled feeding study. Obesity (Silver Spring) 2009; 17: 1664-70.

[27] Salmeron J, Manson JE, Stampfer MJ, Colditz GA, Wing AL, Willett WC. Dietary fiber, glycemic load, and risk of non-insulindependent diabetes mellitus in women. JAMA 1997; 227: 472-7.

[28] Qi L, Rimm E, Liu S, Rifai N, Hu FB. Dietary glycemic index, glycemic load, cereal fiber, and plasma adiponectin concentration in diabetic men. Diabet Care 2005; 28: 1002-28.

[29] Liese AD, Schulz M, Fang F, et al. Dietary glycemic index and glycemic load, carbohydrate and fiber intake, and measures of insulin sensitivity, secretion, and adioposity in the Insulin Resistance Atherosclerosis Study. Diabet Care 2005; 28: 2832-38.

[30] Brand-Miller JC, Hayne S, Petocz P, Colagiuri S. Low-glycemic index diets in the management of diabetes: A meta-analysis of randomized controlled trials. Diabet Care 2003; 26: 2261-7.

[31] Jenkins DJA, Kendall CWC, McKeown-Eyssen G, et al. Effect of a low-glycemic index or a high-cereal fiber diet on type 2 diabetes. JAMA 2008; 300: 2742-53

[32] Wolever TM, Mehling C, Chiasson JL, et al. Low glycaemic index diet and disposition index in type 2 diabetes (the Canadian trial of carbohydrates in diabetes): a randomized controlled trial. Diabetologia 2008; 51: 1606-15

[33] Willett WC, Manson J, Liu S. Glycemic index, glycemic load, and risk of type 2 diabetes. Am J Clin Nutr 2002; 72(suppl): 274S-80S.

[34] Dickinson S, Brand-Miller J. Glycemic index, postprandial glycemia and cardiovascular disease. Curr Opin Lipidol 2005; 16: 69-75.

[35] Opperman AM, Venter CS, Oosthuizen W, Thompson RL, Vorster $\mathrm{HH}$. Meta-analysis of the health effects of using the glycemic index in meal-planning. Br J Nutr 2004; 92: 367-81.

[36] Liu S, Willett WC, Stampfer MJ, et al. A prospective study of dietary glycemic load, carbohydrate intake, and risk of coronary heart disease in U.S. women. Am J Clin Nutr 2000; 71: 1455-61.
[37] Levitan EB, Cook NR, Stampfer MJ, et al. Dietary glycemic index, glycemic load, blood lipids, and C-reactive protein. Metabolism 2008; 57 : 437-43.

[38] Sloth B, Krog-Mikkelsen I, Flint A, et al. No difference in body weight decrease between a low-glycemic-index and a highglycemic-index diet but reduced LDL cholesterol after 1-wk ad libitum intake of the low-glycemic-index diet. Am J Clin Nutr 2004; 80: $337-47$

[39] Shikany JM, Goudie A, Oberman A. Comparison of a low-fat/lowglycemic index diet to a low-fat only diet in the treatment of adults with hypercholesterolemia. Nutr Res 2005; 25: 971-81.

[40] Shikany JM, Phadke RP, Redden DT, Gower BA. Effects of lowand high-glycemic index/glycemic load diets on coronary heart disease risk factors in overweight/obese men. Metabolism 2009; 58: 1793-801.

[41] Ebbeling CB, Leidig MM, Sinclair KB, Seger-Shippee LG, Feldman HA, Ludwig DS. Effects of an ad libitum low-glycemic load diet on cardiovascular disease risk factors in obese young adults. Am J Clin Nutr 2005; 81: 976-82.

[42] Gnagnarella P, Gandini S, La Vecchia C, Maisonneuve P. Glycemic index, glycemic load, and cancer risk: a meta-analysis. Am J Clin Nutr 2008; 87: 1793-81

[43] Esfahani A, Wong JMW, Mirrahimi A, Srichaikul K, Jenkins DJA, Kendall WC. Glycemic index: Physiological significance. J Am Coll Nutr 2009; 28: 439S-45S.

[44] Chiu C-J, Hubbard LD, Armstrong J, et al A. Dietary glycemic index and carbohydrate in relation to early age-related macular degeneration. Am J Clin Nutr 2006; 83: 880-6.

[45] Schaumberg DA, Liu S, Seddon JM, Willett WC, Hankinson SE Dietary glycemic load and risk of age-related cataract. Am J Clin Nutr 2004; 80: 489-95.

[46] Cheng IS, Liao SF, Liu KL, et al. Effect of dietary glycemic index on substrate transporter gene expression in human skeletal muscle after exercise. Eur J Clin Nutr 2009; 63: 1404-10.

[47] Mettler S, Lamprecht-Rusca F, Stoffel-Kurt N, Wenk C, Colombani PC. The influence of the subjects' training state on the glycemic index. Eur J Clin Nutr 2007; 61: 19-24.

[48] Bell SJ, Van Ausdal W, Grochoski G. Appetite, body weight, health implications of a low-glycemic-load diet. In: Bagchi D, Preuss HG, Eds. Obesity: Epidemiology, Pathophysiology, and Prevention. Boca Raton: CRC Press 2007; pp. 245-64.

[49] Keast DR, Jones JM. Dried fruit consumption associated with reduced overweight or obesity in adults: NHANES, 1999-2004. FASEBJ 2009; 23LB511 (abstract).

[50] Kim Y, Hertzler SR, Byrne HK, Mattern CO. Raisins are low to moderate glycemic index food with a correspondingly low insulin index. Nutr Res 2008; 28: 304-8.

[51] Gutschall ND, Miller CK, Mitchell DC, Lawrence FR. A randomized behavioural trial targeting glycaemic index improves dietary, weight and metabolic outcomes in patients with type 2 diabetes. Public Health Nutr 2009; 12: 1846-54

[52] LaMonte D, Fadavi S, Koerber A, We CD. Effects of raisincontaining cereals on acidogenicity of dental plaque. International Association for Dental Research and the American Association for Dental Research, Honolulu, Hawaii, abstract, March 10-14, 2004.

[53] Sacheck JM, Kafka T, Rasmussen H, Blumberg JB, Economos CD The impact of pre exercise snacks on exercise intensity, stress, and fatigue in children. Med Sci Sports Exerc 2009; 41: 105, abstract.

[54] Kern M, Heslin CJ, Rezende RS. Metabolic and performance effects of raisins versus sports gel as pre-exercise feedings in cyclists. J Strength Cond Res 2007; 21: 1204-7. 